\title{
Comparing overflow and wave-overtopping induced breach initiation mechanisms in an embankment breach experiment
}

\author{
Myron van Damme ${ }^{1, a}$, Luc Ponsioen ${ }^{1}$, Monica Herrero ${ }^{2}$ and Patrik Peeters ${ }^{3}$ \\ ${ }^{1}$ Delft University of Technology, Department of Hydraulic Engineering, $2628 \mathrm{CN}$, Delft, The Netherlands \\ ${ }^{2}$ Delft University of Technology, Department of Optical and Laser Remote sensing, 2628CN, Delft, The Netherlands \\ ${ }^{3}$ Flanders Hydraulics Research, Department of Mobility and Public Works, 2140, Antwerp, Belgium
}

\begin{abstract}
As part of the SAFElevee project Delft University of Technology collabored with Flanders Hydraulics Research, and Infram B.V. in the preperation and execution of a full scale embankment breach experiment in November 2015. This breach experiment was performed on an $3.5 \mathrm{~m}$ high embankment with a sand core and clay outer layer situated along the tidal river Scheldt in Belgium near Schellebelle. During the experiment a wave overtopping simulator and overflow simulator were used to initiate a breach. Both simulators were placed near the top of the waterside slope. The use of the simulators facilitated comparison between the effects of continueous overflow and the effects of intermittent wave overtopping. This paper presents the data collected during the experiment, describe the development of hypotheses on the failure processes using the latest insights, and comment on the failure initiation process of a grass covered flood embankment with a clay outer layer and a sandy core.
\end{abstract}

\section{Introduction}

Experimental studies to failures of embankments are dominated by experiments on embankments of homogeneous material as performed under the EU IMPACT project [1], at the Chiyoda experimental channel [2], or in Belgium as part of the Sigma plan [3]. Failure is thereby often initiated due to overflow. This limits the validation of breach models that aim to simulate breach initiation and formation due to wave overtopping and the failure of layered structures.

Due to relocation of an embankment as part of the Sigma plan [3] the former flood embankment along the river Scheldt, bordering the Weimeers-2 polder near Schellebelle, had become redundant. It was therefore selected to serve as a test embankment on which to study the differences in processes of breach initiation and formation due to overflow and wave overtopping. The full scale experiment was performed by Flanders Hydraulic Research, Infram B.V. and Delft University of Technology (as part of the SAFElevee project). The embankment had a sandy core and a clay protection layer on the landside and waterside slope. The thickness of the clay protection layer varied from $60 \mathrm{~cm}$ near the toe of the slopes to approximately $30 \mathrm{~cm}$ near the top of the slopes. The embankment crest was covered with a gravel road. The slopes were covered with a grass cover of poor quality which contained nettles and weeds. The slope gradient of the landside and waterside slope of the embankment were $1 / 1.7$ and the height of the embankment above polder level was $3.5 \mathrm{~m}$.

D'Eliso [4] developed a method for process based modelling of breach initiation and formation ofembankments with a sand core and clay outer layer. The challenge faced by D'Eliso was significant as no detailed experimental data was yet available on the failure processes of this type of embankments. D'Eliso [4] described the failure process of an embankment with a clay cover and grass protection according to several stages: In Stage 1 the cumulated excess shear stress exerted by overtopping waves on the embankment surface leads to localized failure of the grass cover. At these locations the clay cover starts to erode due to headcut formation. The moment the sand core is reached the clay cover is assumed to fail instantaneously due to sliding. The sand core is thereby assumed to erode due to surface erosion processes.

This paper presents a qualitative analysis of the observed failure mechanisms during the experiment and compares this with the process based description by D'Eliso. As the experiment aimed to address the issue of breach initiation, one aspect that cannot be disregarded is the initiation of the grass cover. Section 2 describes the test methodology applied whereby Section 2.1 describes the three different theories with respect to grass failure which formed the basis for the experimental setup;

\footnotetext{
a Corresponding author: m.vandamme@tudelft.nl
} 
Section 2.2 focusses on the overtopping experiments and Section 2.3 on the overflow experiment. Test results are describes in Section 3. A discussion is given in Section 4 and conclusions in Section 5.

\section{Test methodology}

Over an approximate $50 \mathrm{~m}$ long stretch of embankment, two tests were performed on breach initiation due to wave overtopping using the $4 \mathrm{~m}$ wide wave overtopping simulator developed by Van der Meer [5], [6][7]. Also two breach initiation experiments had been performed using a $2 \mathrm{~m}$ wide overflow simulator developed specifically for this experiment by Delft University of Technology. An overview of the test sections has been depicted in Figure 1.

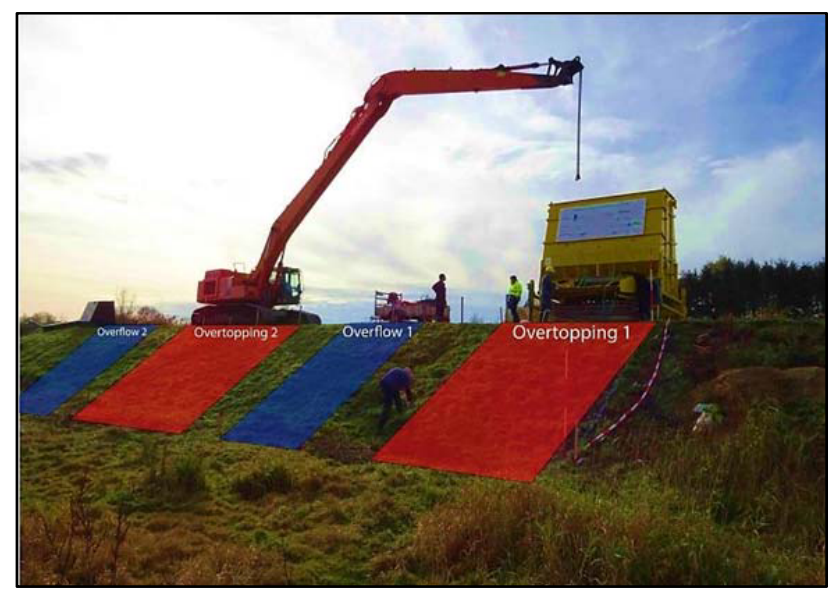

Figure 1. Overview test locations on embankment.

At intermittent time steps the damage was recorded using video and photographic cameras. A Leica C10 laser was applied at intervals of maximum 1 hour to quantify the temporal change in geometry from which also local erosion rates could be derived. For each experiment the sides of the test sections were cordoned off with wooden plates held in place by wooden pickets. The waveovertopping and overflow simulator were placed on the waterside slope in such a way that the outflow openings of the simulators were at crest level. A frequentially adjustable pump with a capacity of $400 \mathrm{~m}^{3} / \mathrm{hr}$ was used to pump water from the river Scheldt into the simulators. A diesel generator provided the energy needed to operate the pumps and simulator controls.

\subsection{Grass failure conditions}

The grass cover was of low quality with a large fraction of weeds and nettles. Based on previous experience of Infram B.V. with overtopping experiments on grass covered embankments, damage was anticipated to occur at mean overtopping discharges of 10 or $251 / \mathrm{m} / \mathrm{s}$. Different methods have been used to identify the overflow conditions under which the grass cover would fail.

\subsubsection{CIRIA manual on grass protections}

A critical flow velocity needed to initiate failure of the grass cover is given by Technical Note 71 [8], which underlies the CIRIA 116 manual on grass [9][10]. According to this technical note low quality grass should fail when subjected to flow velocities of approximately 2 to $2.5 \mathrm{~m} / \mathrm{s}$. The critical shear strength of grass is thereby expected to show a logarithmic decrease over time. A flow of approximately $2.5 \mathrm{~m} / \mathrm{s}$ corresponds with shear stresses of $75 \mathrm{~N} / \mathrm{m}^{2}$ under the assumption of a hydraulically smooth surface with a Manning coefficient of $0.025 \mathrm{~s} / \mathrm{m}^{1 / 3}$.

\subsubsection{Laboratory experiments}

As part of the experiment, laboratory tests were performed to the shear resistance of the grass and clay cover which indicated that failure would occur at shear stresses of $24 \mathrm{~N} / \mathrm{m}^{2}$.

\subsubsection{Model of Hughes and Dean.}

Dean, et al. [11] assumed that the landside slope of an embankment is resistant against the energy transferred by the flow to the bed above a threshold value for a certain time. Acceptable erosion occurs on the landside slope until the cumulative excess energy transferred exceeds the grass-damage threshold. Thus, for every overtopping wave in which the flow velocity is greater than the critical velocity, there will be a contribution to the accumulated total energy transfer represented by

$$
\sum_{n=1}^{N}\left(u^{3}-u_{c W}^{3}\right) \Delta t_{n} \leq \frac{E_{W}}{K_{W} \mathrm{~B}_{W}}
$$

Where $u$ is the flow velocity, $N$ is the amount of overtopping events and $\Delta t_{n}$ is the wave overtopping duration. The right hand side denotes a measure for the acceptable erosion on the landside slope. This equation was extended by Hughes [12] into

$$
\sum_{n=1}^{N} V_{w n}\left[1-\left(\frac{q_{c} T_{o n}}{V_{w n}}\right)+0.38\left(\frac{q_{c} T_{o n}}{V_{w n}}\right)\right] \leq \frac{E_{W} f_{F}}{\alpha K_{W} \mathrm{~B}_{W}}
$$

where $V_{w n}$ is the total volume of the $\mathrm{n}_{\text {th }}$ overtopping wave, $T_{o n}$ is the overtopping time of the $n_{\text {th }}$ individual overtopping wave, $\alpha=2 g \sin \theta$, and

$$
q_{c}=f_{F} u_{c}^{3} /(2 g \sin \alpha)
$$

The parameter $u_{c}$ and the left hand side of Equation 1 is a constant related to specific conditions for landside slope covers. The factor $f_{F}$ in Equations 2 and 3 describes the 
influence of external factors. Hughes [12] hypothesized that the excess energy concept could also be applied to overflow conditions. Because a wave overtopping simulator and overflow simulator had been applied during the experiment all overtopping volumes of the waves were a-priori known and could easily be substituted in Equation 2. The right hand side of Equation 2 describes the degree of damage on a levee and will further on be denoted by the symbol $D_{E}$. Both the grass strength curves from the TN71, as Equation 1 clearly show a time dependent shear resistance of grass. However, where Dean et al. [11] assumed a linear decrease in erosion resistance above a constant critical value, for development of the TN71 it was assumed that the critical flow velocity decreases approximately logarithmically with time. The moment the critical flow velocity is reached, the grass cover is assumed to have failed. During the experiments the load on the levee was increased when no damage occurred over a period of 2 hours. As the soil becomes more saturated over time the shear strength of the grass is expected to reduce and the failure of the grass cover to initiate more rapidly.

\subsection{Overtopping conditions}

The overtopping experiments were executed for mean overtopping discharges of 1,5,10, and $25 \mathrm{1} / \mathrm{m} / \mathrm{s}$. Each test ran for 2 hours, which exception of the $11 / \mathrm{m} / \mathrm{s}$ test which was accelerated in time, 5 times. The test section was $4 \mathrm{~m}$ wide and cordoned off with $0.6 \mathrm{~m}$ high wooden boards on either side. The gravel road was covered with a plastic sheet up to where it connected with the grass cover to prevent erosion of the crest during the experiment. The overtopping volumes released from the overtopping simulator were obtained by sampling from a Weibull distribution with the shape and scale parameters given in Table 1. These factors are based on a breaker parameter of 1.5 and an assumed wave steepness of 0.04 . It was decided to use quite steep waves to limit the ratio between the wave length and the length of the landside slope. The shorter wave length allowed for smaller overflow discharges while maintaining a similar mean shear stress on the landside slope.

\begin{tabular}{|l|l|l|l|l|l|}
\hline $\mathrm{q} 1 / \mathrm{s} / \mathrm{m}$ & $\mathrm{H}_{\mathrm{s}}[\mathrm{m}]$ & $\mathrm{Tm}[\mathrm{s}]$ & $\mathrm{P}_{\mathrm{ot}} \%$ & $\begin{array}{l}\text { Scale } \\
\text { factor }\end{array}$ & $\begin{array}{l}\text { Shape } \\
\text { factor }\end{array}$ \\
\hline 1 & 0.4 & 2.11 & 18.1 & 0.010 & 0.770 \\
\hline 5 & 0.6 & 2.58 & 33.6 & 0.035 & 0.836 \\
\hline 10 & 0.8 & 2.98 & 38.6 & 0.071 & 0.858 \\
\hline 25 & 1.2 & 3.65 & 44.9 & 0.192 & 0.887 \\
\hline
\end{tabular}

Table 1. Shape and scale parameters of the Weibull distribution used for determining the overtopping volumes in $\mathrm{m}^{3} / \mathrm{m}$

To assess the roughness parameters on the embankment, hydraulic measurements were performed with waves of respectively 500, 1000, 1500, 2000, 2500, 3000, and $3500 \mathrm{l} / \mathrm{m}$. During the hydraulic measurements the flow velocities were continuously measured at the bed and surface of the waves using paddle-wheels. To measure the change in depth profile of a wave over time, a surfboard like construction was used (see Figure 2). The water depth was derived from measuring the change in angle of the surfboards when a wave passed under it. The paddle-wheels were placed near the downstream tip of the surfboard, both in the embankment surface and on the tip of the surfboard. This way both the flow velocity at the bed and at the surface could be measured. The front velocity of the wave was derived by measuring the time lapse in signal from the surfboards and the known distance between two surfboards.

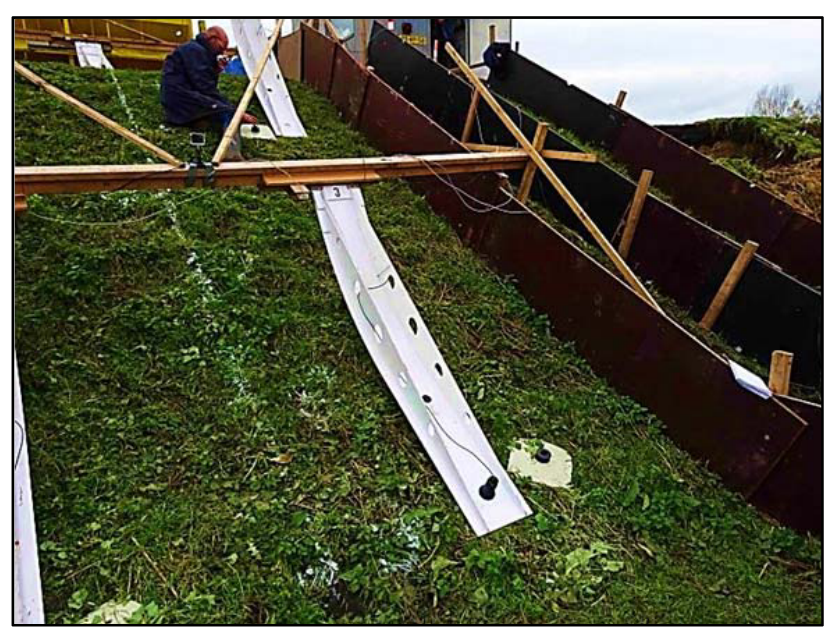

Figure 2. Setup for performing hydraulic measurements during wave overtopping tests.

\subsection{Overflow conditions}

The aim in determining the overflow conditions has been to find those overflow conditions for which the critical stresses under equilibrium flow conditions on the landside slope are comparable to those exerted during wave overtopping events. For the initiation of failure of the grass cover larger wave volumes are expected to be more damaging than smaller ones as the excess energy (or shear stress) transferred on the embankment are more likely to exceed the strength of grass. As values were determined experimentally on the shear strength of the grass it was decided to relate the shear stresses during overflow with those exerted during wave overtopping. For the failure of grass the mean excess shear stress was derived for those volumes exceeded by $5 \%$ of the overtopping waves indicated by $\tau_{95}$. This shear stress was then added to the value of $\tau_{95}$ and used to derive the corresponding overflow conditions. To achieve this, the peak discharge per overtopping wave was obtained from the volumes $V$ drawn from the Weibull distribution with the scale and shape parameters given in Table 1 . The peak discharge was obtained from the overtopping volume using Equation 4 [13].

$$
q_{p}=0.184 \sqrt{g} V^{\frac{3}{4}}
$$

Where $q_{p}$ is the peak overtopping discharge per wave, and $g$ is the gravitational constant. The overtopping time per wave $T_{o}$ was obtained from Equation 5 [13]. 


$$
\mathrm{T}_{\mathrm{o}}=\frac{\mathrm{V}^{1.16}}{0.43 \mathrm{q}_{\mathrm{p}}}
$$

The change in discharge with time was assumed to be described by

$$
q(t)=q_{p}\left(1-\frac{t}{T_{o}}\right)^{m}
$$

The local deceleration of an overtopping wave at $t=0$ could be described by

$$
\frac{\partial \mathrm{q}}{\partial \mathrm{t}}=\frac{-\min \left\{\max \left[\left(2.33 \mathrm{~V}^{0.16}-1\right), 1\right], 2\right\}}{\mathrm{T}_{0}} \mathrm{q}_{\mathrm{p}}
$$

Whereby the power $m$ in Equation 6 is equal to the numerator on the right hand side of Equation 7. Accounting for the effects of the local deceleration (see Equation 7) in the equation of Belanger gives a peak normal depth of overtopping waves which is approximately twice the normal depth during a steady state overflow. The effects of local deceleration at the wave front have thus far been neglected in the derivation of the change in depth profile at the front of the wave by Schuttrumpf and Van Gent [14]-[16]. The average factor of 2 found in this analysis showed that the effect of the local deceleration on the change in depth is significant and should be accounted for. Here the normal depth has therefore been approximated by

$$
d_{n} \approx 2\left(\frac{q_{p}^{2} n^{2}}{\tan (\alpha)}\right)^{0.3}
$$

whereby a manning parameter $n$ of $0.025 \mathrm{~s} / \mathrm{m}^{1 / 3}$ was used. During an overtopping event the peak discharge approximately coincides with the peak flow velocity and peak depth. Hence from the peak discharge and depth the peak velocity follows. Manning's equation was then used to determine the peak shear stress. In line with the description of the change in depth and velocity as given by Hughes et al. [13] the change in shear stress with time is given by

$$
\tau(t)=\tau_{p}\left(1-\frac{t}{T_{o}}\right)^{s}
$$

Where $s$ is given by

$$
\mathrm{s}=\min \left(\max \left(\left(4.66 V^{0.16}-4.33\right), \frac{5}{3}\right), \frac{10}{3}\right)
$$

A time $t_{1}$ was defined at which the shear stress equals $\tau_{95}$ From integrating Equation 9 from $t=0$ to $t=t_{1}$ and dividing by $t_{1}$ the mean excess shear stress per overtopping wave is obtained. This mean excess shear stress was added to the shear stress exceeded by $5 \%$ of the overtopping waves $\tau_{95}$ to arrive at a comparable shear stress per wave for the overflow conditions. The same process was repeated whereby $\tau_{95}$ was replaced by $\tau_{0}$, which indicates that the critical shear stress is negligible compared to the applied stresses. Using Manning's formula the mean excess shear stress was converted into a velocity, which combined with the normal depth formed the corresponding overflow discharge. This process was repeated for wave volumes drawn from the Weibull distribution with the shape and scale parameters given in Table 1 to arrive at a mean shear stress for all waves. Table 2 presents those flow conditions for which the mean shear stress is exceeded by $5 \%$ of the overtopping waves. Those overflow conditions which correspond with the mean shear stress exerted by overtopping waves are given in Table 3.

\begin{tabular}{|l|l|l|}
\hline $\begin{array}{l}\mathrm{q}_{\text {ave }}[1 / \mathrm{s} / \mathrm{m}] \\
\text { (waves) }\end{array}$ & $\mathrm{q}_{\mathrm{f}}[1 / \mathrm{m} / \mathrm{s}]$ (flow) & $\tau_{\text {ave }}\left[\mathrm{N} / \mathrm{m}^{2}\right]$ \\
\hline 1 & 4 & 24 \\
\hline 5 & 9 & 40 \\
\hline 10 & 14 & 55 \\
\hline 25 & 28 & 84 \\
\hline
\end{tabular}

Table 2. Comparable overflow conditions for those mean overtopping discharges for which $5 \%$ of the overtopping waves exceeded shear stress

\begin{tabular}{|l|l|l|}
\hline $\begin{array}{l}\mathrm{q}_{\text {ave }}[1 / \mathrm{s} / \mathrm{m}] \\
\text { (waves) }\end{array}$ & $\mathrm{q}_{\mathrm{f}}[1 / \mathrm{m} / \mathrm{s}]$ (flow) & $\tau_{\text {ave }}\left[\mathrm{N} / \mathrm{m}^{2}\right]$ \\
\hline 1 & 0.2 & 4.0 \\
\hline 5 & 0.5 & 7.3 \\
\hline 10 & 0.8 & 10 \\
\hline 25 & 1.5 & 16 \\
\hline
\end{tabular}

Table 3. Comparable overflow conditions for which the mean shear stress equals the mean shear stress during overtopping.

The discharges given in Table 3 are quite small. The cause of this is the short moment in time during an overtopping event at which the flow velocities and depths are maximum.

During the analysis for the development of Tables 2 and 3 it was noted that the depths, for which the bed shear stress under equilibrium flow conditions matches the bed shear stresses given in the tables, become small compared to the height of the grass. This hence gives relatively high flow velocities. Due to the relatively small length of the landside slope the flow full equilibrium conditions may not have been reached. Hence the flow velocities were considered to be an upper bound. Therefore a pump used which would be able to sustain a flow of $85 \mathrm{l} / \mathrm{m} / \mathrm{s}$ over a $2 \mathrm{~m}$ wide test section. This experiment would have taken place on two locations.

During the overflow experiments, the discharge was measured using an acoustic discharge meter which was placed on the pipe towards the simulator. Flow velocities were obtained during hydraulic measurements using peddle-wheels, by tracking warm floaters using a FLIR A35 infrared cameras placed over the test section, and indirectly from measuring water depths using a ruler and dividing the discharge by the known width of the flow section and measured water depth. 


\section{Results}

\subsection{Overtopping tests}

First the wave overtopping experiments were performed. The first experiment consisted of 24 minutes of testing at a mean overtopping discharge of $1 \mathrm{l} / \mathrm{m} / \mathrm{s}$ accelerated 5 times because of the small amount of water. Subsequently test waves were simulated with mean overtopping discharges of 5,10 and $251 / \mathrm{m} / \mathrm{s}$.

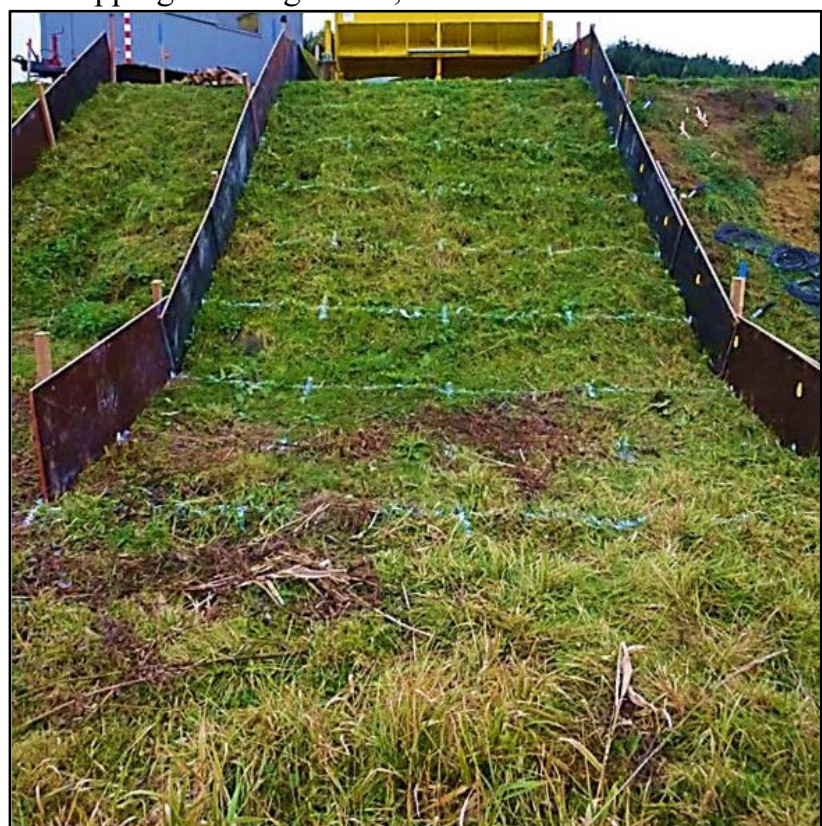

Figure 3. Overview picture taken prior to the first wave overtopping experiment

Prior to the tests the embankment was divided into $1 \times 1 \mathrm{~m}$ quadrants (see Figure 3). The first quadrant (1A) started on the far left hand side of the outflow point of overtopping simulator. The flow channel was $4 \mathrm{~m}$ wide. Across, it was divided into Sections A through D with A being on the left hand side looking upstream. In total 11 cross sections were created. During the first test cross sections 1, 2, and the first half of cross section 3 were fully covered with a plastic sheet to prevent erosion of the gravel road. Between the end of the plastic sheet and the top of the landside slope some flattened grass cover was present. On the landside slope several stones were present. In Section 4A a small hole was visible. In cross sections $6 \mathrm{~A}$ and $8 \mathrm{C}$ stones were visible from the surface. In section 7 the nettles and moss were visible. In general the grass cover was not nice and smooth but represented a rough surface. Characteristic of the behaviour of grass under the wave loading was that every time the wave had passed the grass bounced back into an upright position. This could therefore have contributed to a higher roughness experienced by the waves and hence higher shear stresses.

During the $10 \mathrm{l} / \mathrm{m} / \mathrm{s}$ it was noted a hole had formed with a diameter of approximately $0.2 \mathrm{~m}, 1 \mathrm{~m}$ below the top of the landside slope in Section 4A. Further analysis showed that this was a rabbit hole. Water infiltrating the rabbit hole caused for erosion and the formation of a hole near the outflow, which was located $5 \mathrm{~m}$ west of the test site. At the end of the $10 \mathrm{l} / \mathrm{m} / \mathrm{s}$ test, the hole had grown to approximately $0.5 \mathrm{~m}$ deep. During the $25 \mathrm{l} / \mathrm{m} / \mathrm{s}$ the hole in on the slope increased in size. After 3 minutes, part of the grass cover came loose near the hole. After $12 \mathrm{~min}$ the sand layer was reached in the hole. Once the sand layer was reached a trench developed due to erosion downstream of the hole (see Figure 4)

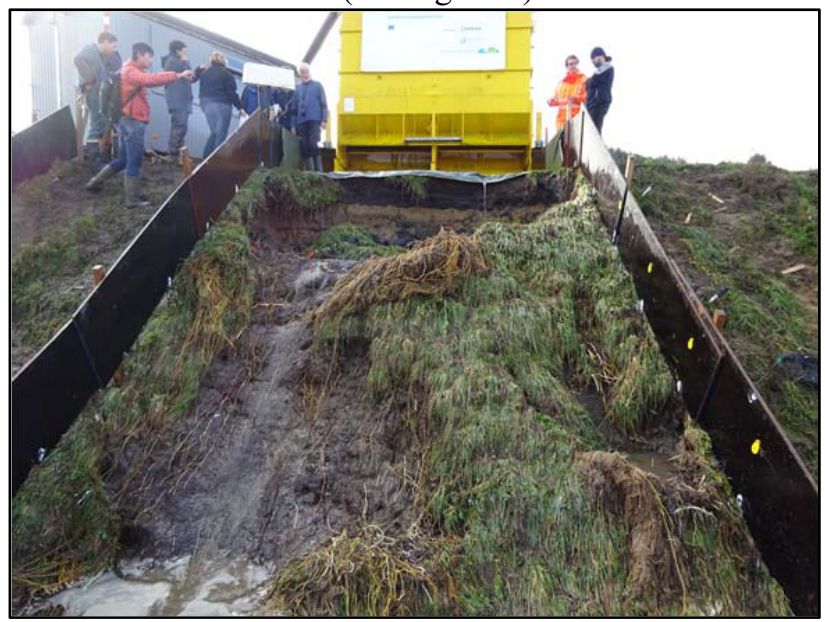

Figure 4. Overview picture taken at the end of the $25 \mathrm{l} / \mathrm{m} / \mathrm{s}$ tests at the first test section

Simultaneously headcut erosion caused for the upstream progression of the hole. The sand under the clay layer acted reasonably cohesive maintaining near vertical slopes. The processes observed during the retreat of the landside slope were similar to the underwater breaching process as observed during dredging at sand pits. Here the dilation of sandy soil due to water infiltration in combination with the reduction of negative pore pressures determine the rate of erosion and prevent large scale slope failures from occurring.

After the first experiment was completed hydraulic measurements were taken on the second test section. When the $30001 / \mathrm{m}$ waves were released over the dike damage to the grass cover initiated instantaneously giving an indication of the strength of the grass cover under loading of a single wave. Hence prior to the 2 hour long test at $25 \mathrm{l} / \mathrm{m} / \mathrm{s}$ which was performed on this test section already some bold spots had formed in the grass cover near the toe of the landside slope. After 1 hour of testing an erosion hole had formed on the slope $2.5 \mathrm{~m}$ downstream of the top of the landside slope. Hence the initial damage at the toe was of negligible influence of the rest of the experiment. Analysis of the video material showed that the damage initiated at the location where the larger waves impacted on the landside slope of the levee after being separated at the intersection of the crest and the landside slope (see Figure 5). After 1 hour and 20 minutes the sand layer was reached causing for rapid erosion and headcut formation. Seven minutes after the sand layer was reached the experiment was stopped to prevent danger to the overtopping simulator. 


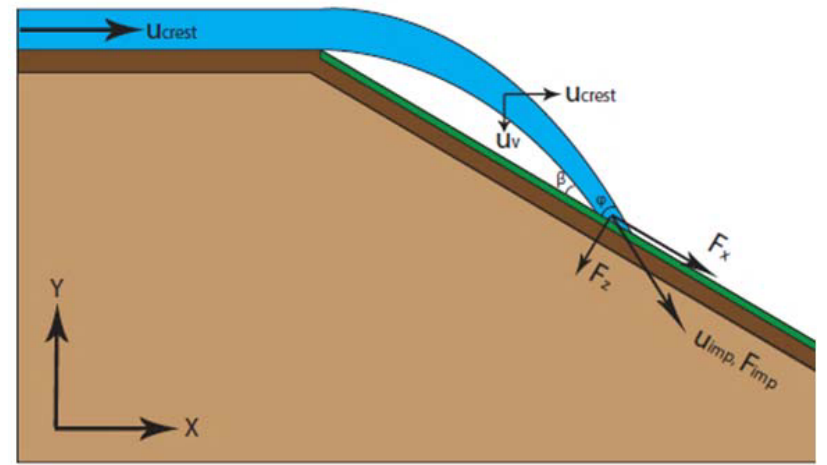

Figure 5. Description of the wave impact on the landside slope.

\subsection{Overflow}

Due to limitations in the minimum allowable frequency at which the pump could be operated, tests with the overflow simulator started at $10 \mathrm{l} / \mathrm{m} / \mathrm{s}$, followed up by $25,50 \mathrm{l} / \mathrm{m} / \mathrm{s}$ and $85 \mathrm{l} / \mathrm{m} / \mathrm{s}$. Contrary to expectations, the damage that occurred to the grass cover at overflow discharges of $501 / \mathrm{m} / \mathrm{s}$ and $851 / \mathrm{m} / \mathrm{s}$ was negligible. Instead of the theoretical nice smooth flow of constant density, during all overflow tests the flow became highly aerated down the landside slope (see Figure 6). This could be of influence to the spatial velocity distribution down the slope. Between changes in the discharge the flow was stopped during which became apparent that contrary to the behaviour of grass during wave overtopping the grass cover remained in a flattened position and did not bounce back upwards. Another noticeable, and potentially important observable difference with the wave overtopping tests, was that during overflow the reattachment point of the flow was closer to the crest than during wave overtopping. The normal impact at the reattachment point is therefore also expected to be smaller during overflow than during wave overtopping. These differences with wave overtopping could potentially help in better explaining the difference in timing in failure initiation of the grass cover.

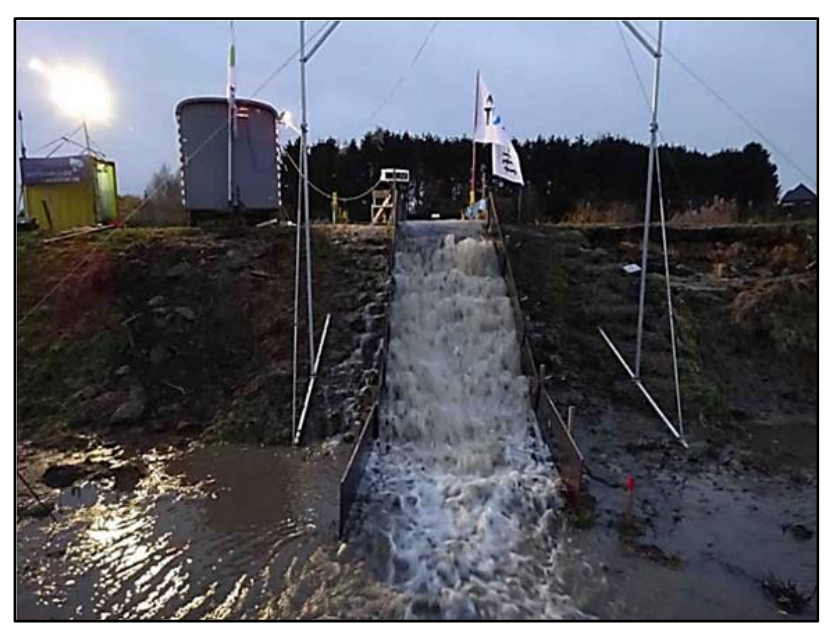

Figure 6. Observed aerated flow during the overflow experiment
To initiate damage of the grass cover the width of the test section was reduced to $1 \mathrm{~m}$ to enable flows up to 170 $1 / \mathrm{m} / \mathrm{s}$. Experiments were then performed with flows of 125 and $170 \mathrm{l} / \mathrm{m} / \mathrm{s}$. The effects of the aeration remained significant leading to an average flow velocity along the entire landside slope of approximately $2.9 \mathrm{~m} / \mathrm{s}$ at 125 $1 / \mathrm{m} / \mathrm{s}$ and $3.2 \mathrm{~m} / \mathrm{s}$ at $170 \mathrm{l} / \mathrm{m} / \mathrm{s}$. The flow velocity increased along the landside slope as was observed using hot particle tracking with an infrared camera (see Figure 7). The higher flow resulted in a theoretical shear stress, corresponding to the mean velocity on the landside slope, of $167 \mathrm{~N} / \mathrm{m}^{2}$. This far exceeds the experimentally obtained value of $24 \mathrm{~N} / \mathrm{m}^{2}$ of the grass layer. Subjected to flows of $170 \mathrm{l} / \mathrm{m} / \mathrm{s}$ the damage to the grass cover started to increase around weak spots in the grass cover where large stones were present. However progression of the failure was small and due to time restraints it was necessary to relocate.

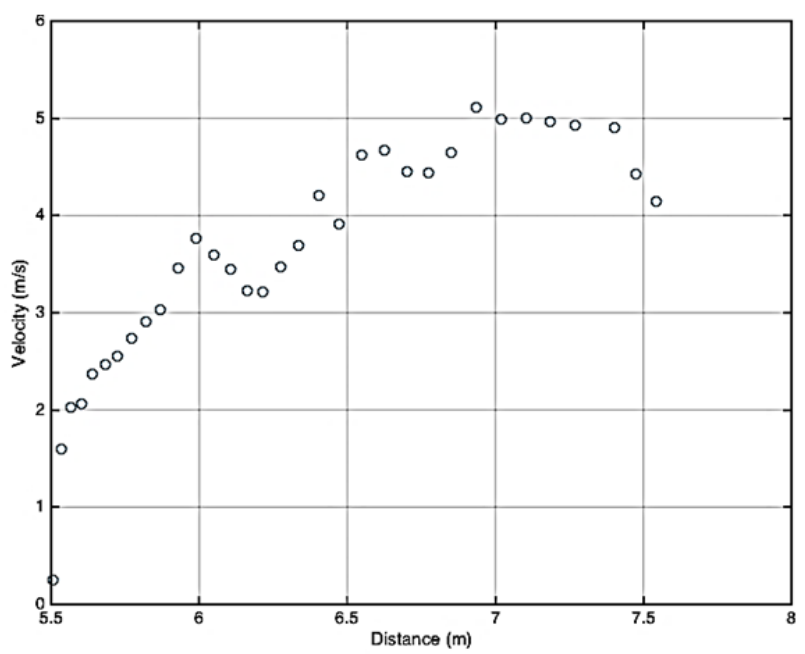

Figure 7. Measured magnitude of the flow velocity component down the landside slope as a function of distance along the landside slope at a discharge of $170 \mathrm{1} / \mathrm{m} / \mathrm{s}$. Distance 0 is at the exit of the overflow simulator.

At the new location the two meter wide test section was split into half. On one side the grass cover was left intact and on the other side the grass cover was carefully removed using the available excavator, exposing the grass roots and the clay cover. Near the toe of the exposed section a larger fraction of clay was unfortunately removed with removal of the grass cover leading to a slight depression in the initial profile of the embankment (see Figure 7). The grass covered test section was subjected to a flow of $170 \mathrm{l} / \mathrm{m} / \mathrm{s}$ for a period of two hours to see whether any damage could be obtained. The lack of damage formation supported the idea that grass has a much larger residual strength than obtained from measurements and based on available literature. After this a flow of $301 / \mathrm{m} / \mathrm{s}$ was directed over the exposed test section. This caused for headcut formation to start at the location of the depression (see Figure 7$)$. The point $(0,0)$ refers to the intersection of the crest and landside slope. 


\subsection{Grass failure behaviour}

The performed experiments have provided the unique opportunity to compare the impact of overtopping waves with the impact of a steady overflow on the same land side slope of a dike. The strength of the grass cover is considered comparable for the overtopping and overflow experiments. Henceforth, the influence of the external factors is comparable and the friction correction factor $f_{F}$ in Equation 2 becomes irrelevant.. For the application of the Excess energy approximation of Dean and Hughes this means that the term $D_{E}$, given by Equation 11, should be the same for both overtopping and overflow when an equal amount of damage occurs

$$
D_{E}=\frac{E_{W}}{K_{W} \beta_{\mathrm{W}}}\left(\frac{f_{F}}{2 g \sin \theta}\right)
$$

This test therefore provided the means to verify the approach developed by Hughes. The overtopping and overflow experiments resulted in significant damage due to overtopping and negligible damage formation during the overflow experiment. According to the Excess energy approximation this would mean that the value $D_{E}$ as calculated from the overtopping experiments should be significantly higher than $D_{E}$ as calculated from the overflow experiments. The steering files for the overtopping simulator which contain the released overtopping volumes have been substituted in Equation 2 whereby the overtopping time was obtained from Equations 4 and 5. The value for $D_{E}$ that follows has been compared to the same damage factor as calculated by the Excess volume approximation for steady overflow. The results of this comparison are given in Table 6 . During the first experiment waves corresponding with a mean overtopping discharge of $1,5,10$, and $25 \mathrm{1} / \mathrm{m} / \mathrm{s}$ were consecutively released over the landside slope. During the second overtopping experiment only the waves for the hydraulic and the $25 \mathrm{1} / \mathrm{m} / \mathrm{s}$ tests were executed. Hence the damage factor found during the first experiment is higher than the one found during the second experiment. The input values for the excess volume approximation on steady overflow are given in Tables 4 and 5.

\begin{tabular}{|l|l|}
\hline Discharge $\left[\mathrm{m}^{3} / \mathrm{s}\right]$ & Duration $[\mathrm{s}]$ \\
\hline 0.01 & 7200 \\
\hline 0.025 & 7200 \\
\hline 0.050 & 7200 \\
\hline 0.085 & 7200 \\
\hline 0.125 & 7200 \\
\hline 0.170 & 7200 \\
\hline
\end{tabular}

Table 4. Overflow discharges and duration Experiment 1

\begin{tabular}{|l|l|}
\hline Discharge & Duration \\
\hline 0.125 & 3600 \\
\hline 0.170 & 3600 \\
\hline
\end{tabular}

Table 5. Overflow discharges and duration Experiment 2
Values for the damage factor $D_{E}$ for overflow are found by substituting the overflow conditions from Tables 5 and 6 in Equation 1, whereby a conservative value for the critical velocity $u_{c}$ of $1.5 \mathrm{~m} / \mathrm{s}$ is used.

\begin{tabular}{|l|l|}
\hline Experiment & Damage factor $D_{E}$ \\
\hline Overtopping 1 & 2168.5 \\
\hline Overtopping 2 & 679.3 \\
\hline Overflow 1 & 3054 \\
\hline Overflow 2 & 1013 \\
\hline $\begin{array}{l}\text { Table 6. Damage factors found for the overflow and } \\
\text { overtopping experiments }\end{array}$
\end{tabular}

As shown in Table 6 the damage factors are considerably larger for the overflow case than for the overtopping case. Although for both overtopping tests the extent of damage to the grass cover was comparable the damage factor differs significantly.

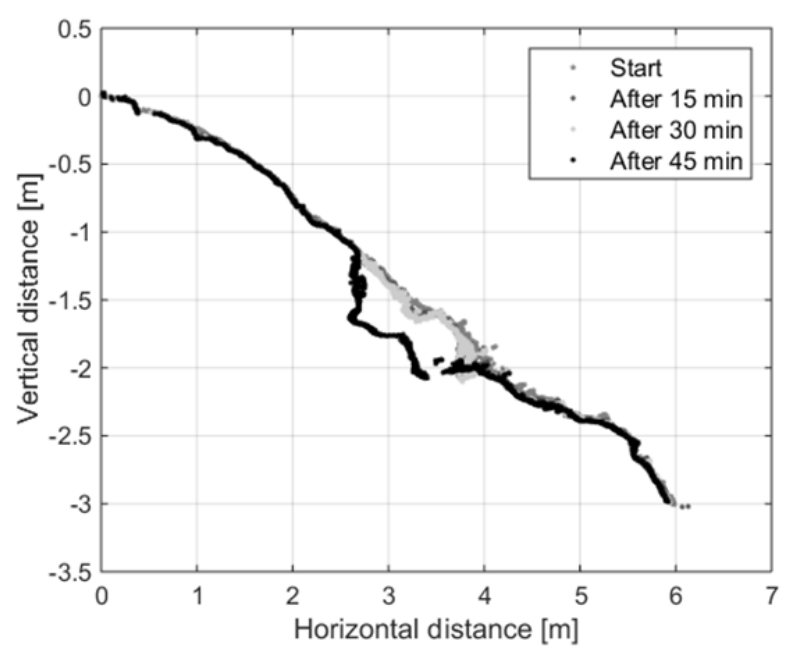

Figure 8. progression in breach initiation to the point the sand layer was reached. Point $(0,0)$ is the intersection of the crest and the landside slope

\section{Discussion}

One of the main surprising observations made during the experiment was the strength of the weak grass cover present on the embankment. The strength of the grass cover under overflow conditions was significantly higher than anticipated. Breach models like the one developed by D'Eliso account for the strength of the grass cover. Unlike the values on grass strength provided in CIRIA 116 , the values in the TN71 do not contain any safety factors [10] and hence underestimate the strength of grass. However as shown by this experiment even the critical flow velocities for grass from TN71 appear conservative. However, the tests performed on the grass covers for the development of TN 71 may actually be on relatively new, and less well rooted grass than was present on the embankment at the test site. For the development of more accurate descriptions of the residual strength of grass covers it is therefore recommended to perform additional tests on well rooted grass. 
Another interesting observation was that the overtopping waves were able to inflict damage to the grass cover whereas an overflow with similar high shear stresses was not able to inflict damage. The damage due to wave overtopping seemed to originate at those locations where the larger waves impacted the landside slope of the embankment. This indicates that the shear stress exerted by waves on a slope is not the dominant loading on the grass cover. The normal forces could also have a great effect as sudden applied normal forces could lead to undrained shallow slope failures that initiate damage to the grass cover. Under wave attack grass stems also had the tendency to move upward again after passing of the waves. Hence as the wave front went over the grass, the grass was subjected to higher stresses than when it would remain flat as was the case under overflow conditions. As much more experiments have been performed on the residual strength of grass under wave attack than under overflow more research in the relation in loading and failure mechanisms between wave overtopping and overflow could significantly benefit the development of relationships for the strength under overflow conditions, as these are also more likely to occur in the case of high water levels in rivers.

In line with the steps indicated by D'Eliso [4], once the grass cover fails locally the clay cover erodes due to headcut erosion. However once the erosion reached the sand core, no slip failures occurred but the embankment continued to erode as the consequence of headcut erosion. This conflicts the failure process description given by D'Eliso [4]. One of the reasons for this may have been that the material in the core has had many years to consolidate. For erosion of material to take place, sand particles need to dilate. This requires an infiltration of water into the soil. Due to this effect solely the top layer of the sand will erode and large scale slip failures were prevented in this case. One should however note that due to the use of overflow and wave overtopping simulators, not the entire core of the embankment was saturated. Under fully saturated conditions the embankment material may behave differently. Although the failure of steep slopes under water are also characterized by very shallow failures and not by large scale failures, as is well known in the field of dredging. The presence of the clay layer also changes the way the flow exerts stresses on the embankment soil. Due to the headcut formation in the clay layer, the flow will describe more of a normal impact on the sand layer. As the large scale failures are prevented it does seem reasonably to assume that the sand will keep failing as part of headcut formation. Undermining of the clay layer due to the retrograde erosion of the sand core will eventually lead to the formation of a full breach.

\section{Conclusions}

As shown by this experiment the breach formation in an embankment with a sand core and clay outer layer describes a headcut formation. The dilation of sandy soil required in combination with the normal impact of the flow on the sand bed is expected to characterise the transient erosive behaviour of the core, and to prevent mass slope failures. The stresses exerted on the embankment surface due to wave overtopping are significantly different than under overflow conditions. More research is recommended to quantify the difference in stresses. The research moreover clearly shows that current theories describing the initiation of failure of grass under overflow could be conservative. The assumption that grass fails due to the shear stresses exerted on the landside slope due to overtopping waves can be falsified as this would require the levee to have failed during overflow as well. The findings that the grass failure initiated at the location where the waves reattached with the landside slope also indicates that the effect of the normal forces due to wave impact have a significant role in grass failure initiation. More research to this is recommended.

\section{References}

1. HR Wallingford, (2005) Investigation of Extreme Flood Processes \& Uncertainty (IMPACT), Breach Formation (WP2), Technical Report: Section 4.

2. Shimada, T., Watanabe, Y., Yokoyama, H., and Tsuji, T. An experiment on overflow-induced crosslevee breach at the Chiyoda Experimental Channel, in River, Coastal and Estuarine Morphodynamics, pp 475-481. Taylor \& Francis Group,Taylor, London.

3. Peeters, P., Zhao, G., De Vos, L., and Visser, P. J. (2015) Large-scale Dike Breaching Experiments at Lillo in Belgium.

4. D'Eliso, C. (2007) Breaching of Sea Dikes Initiated by Wave Overtopping: A Tiered and Modular Modelling Approach.

5. Van der Meer, J. W., Bernardini, P., Snijders, W., and Regeling, E. (2006) The wave overtopping simulator. Coast. Eng. Conf. 4654-4666.

6. Van der Meer, J. W., Steendam, G. J., de Raat, G., and Bernardini, P. (2008) Further developments on the wave overtopping simulator, in $A S C E$, proc. ICCE.

7. Van der Meer, J., Provoust, I., and Steendam, G. . (2012) The wave run-up simulator, theory and First pilot test. Coast. Eng.

8. Whitehead, E., Bull, W., and Schiele, M. (1976) A guide to the Use of Grass in Hydraulic Engineering Practice.

9 Hewlett, H.M., Boorman, L.A. and Bramley, M.E. (1987) Guide to the Design of Reinforced Grass Waterways. CIRIA Report 116. Construction Industry Research and Information Association London.

10 Morris, M.W. Breaching of Earth Embankments and Dams, 2011.

11. Dean, R. G., Rosati, J. D., Walton, T. L., and Edge, B. L. (2010, January) Erosional equivalences of levees: Steady and intermittent wave overtopping. Ocean. Eng. Elsevier.

12. Hughes, S. A. (2011) Adaptation of the levee 
erosional equivalence method for the hurricane storm damage risk reduction system (HSDRRS). USA.

13. Hughes, S., Thornton, C., Van der Meer, J., and Scholl, B. (2012) Improvements in describing wave overtopping processes. Coast. Eng.

14. Van der Meer, J. W., Hardeman, B., Steendam, G. J., Schuttrumpf, H., and Verheij, H. (2011) Flow depths and velocities at crest and landward slope of a dike, in theory and with the wave overtopping simulator. Coast. Eng. Proc. 1, structures-10.

15. Schuttrumpf, H., and Oumeraci, H. (2005) Layer thickness and velocities of wave overtopping flow at seadikes. Coast. Eng. 52, 473-495.

16. Van Gent, M. R. . Low-exceedance wave overtopping events, Measurements of velocities and the thickness of water-layers on the crest and inner slope of dikes. Delft Cluster, Delft, The Netherlands. 